\title{
Hepatic Accumulation and Intracellular Binding of Conjugated Bilirubin
}

\author{
allan W. Wolkoff, Jeanne N. Ketley, Jeanne G. Waggoner, \\ Paul D. BERK, and William B. Jakoby, Section on Diseases of the Liver and \\ Section on Enzymes and Cellular Biochemistry, National Institutes of Arthritis, \\ Metabolism, and Digestive Diseases, National Institutes of Health, Bethesda, \\ Maryland 20014
}

A B S T RACT After the intravenous injection of unconjugated $\left[{ }^{3} \mathrm{H}\right]$ bilirubin into normal Sprague-Dawley and Wistar $R$ rats, radiolabeled bile pigments rapidly accumulated in the liver. By $1.5 \mathrm{~min}$ after injection, an average of $36 \%$ of the injected isotope was present in liver homogenates. Between 3 and 15 min, 37-64\% of the total intrahepatic radiolabeled bilirubin was conjugated, as demonstrated by extraction of label into the polar phase of a solvent partition system. This indicates both rapid conjugation, and accumulation of conjugated bilirubin within the liver cell. Fluorometric determination of the dissociation constants of purified bilirubin and its mono- and diglucuronides for homogeneous preparations of two human and four rat glutathione $S$-transferases, including ligandin, revealed avid binding of all three bile pigments to this class of proteins. Hence, the observation that the intrahepatic bile pigment pool contains substantial amounts of conjugated bilirubin can be attributed to the high binding affinities observed. Thin-layer chromatographic analysis of the ${ }^{3} \mathrm{H}$-pigments produced by $\boldsymbol{p}$-iodoaniline diazotization of homogenates and cytosol demonstrated that the intrahepatic pool of conjugated bilirubin was almost exclusively monoglucuronide. Examination of radiolabeled bilirubin conjugates excreted in bile during the first $20 \mathrm{~min}$ after injection of $\left[{ }^{3} \mathrm{H}\right]$ bilirubin showed no preferential excretion of diglucuronide. These studies indicate that $(a)$ both bilirubin and its monoglucuronide accumulate within the liver cell as ligands with the glutathione $S$-transferase; and $(b)$

Dr. Wolkoff's present address is Department of Medicine, Albert Einstein College of Medicine, Bronx, New York. Dr. Ketley's is Bureau of Foods, Food and Drug Administration, Washington D. C. Dr. Berk's is Hematology Science, Mount Sinai Medical School, City University of New York, New York.

Received for publication 13 July 1977 and in revised form 18 August 1977. bilirubin diglucuronide does not significantly accumulate within the general intrahepatocellular pool of protein-bound bile pigments. The latter observation is compatible with the formation and excretion of bilirubin diglucuronide directly from the canalicular pool of the liver cell.

\section{INTRODUCTION}

Hepatic excretion of organic anions is believed to proceed by several discrete but interrelated processes: uptake by the hepatocyte, "storage", conjugation, and excretion into bile $(1,2)$. In particular, bilirubin is selectively transported into the hepatocyte (3), bound there to specific cytoplasmic proteins (4), conjugated to more polar compounds (5), and actively transferred to the bile canaliculus $(2,6)$. The presence of intrahepatocellular macromolecules with high affinity for bilirubin has been localized to two protein fractions designated as $\mathrm{Y}$ (ligandin) and $\mathrm{Z}(4,7,8)$ of which the former appears to be quantitatively more important with respect to bilirubin binding (4). Recently, homogeneous preparations of rat ligandin and glutathione $S$-transferase B were demonstrated to be identical (9). This transferase is one of a class of enzymes that catalyzes the conjugation of glutathione to a large number of electrophilic substrates (10-12) and acts as well in the catalysis of another group of reactions wherein glutathione serves as a nucleophile $(10,13,14)$. Each of the five rat (10) and five human (15) glutathione $S$-transferases that have been purified to homogeneity has been found to bind bilirubin and other compounds as nonsubstrate ligands (16).

Reports have suggested that once bilirubin is conjugated, its affinity for these cytoplasmic-binding proteins is reduced (17), and it is rapidly excreted without intracellular accumulation (18). The present study was undertaken to examine these conclusions. 
The content of conjugated bilirubin was determined directly in homogenates and cytosol from rat liver by solvent partition, and thin-layer chromatographic techniques after intravenous injection of radioactive bilirubin. In addition, the availability of highly purified preparations of bilirubin monoglucuronide and diglucuronide (19) as well as unconjugated bilirubin, has allowed direct fluorometric determination of their affinities for the several rat and human glutathione $S$-transferases.

\section{METHODS}

Bilirubin ${ }^{1}$ was obtained from the Sigma Chemical Co., St. Louis, Mo. $\left[{ }^{3} \mathrm{H}\right]$ Bilirubin $(100 \mathrm{mCi} / \mathrm{mmol})$ was prepared $(20)$ from dog bile collected after intravenous injection of $\alpha-\left[2,3-{ }^{3} \mathrm{H}\right]$ aminolevulinic acid (33 $\mathrm{mCi} / \mathrm{mmol}$; Schwarz/ Mann Div., Becton, Dickinson \& Co., Orangeburg, N. Y.) Unlabeled conjugated bilirubin was purified from bile obtained from Wistar R-strain rats by affinity chromatography on albumin-agarose gel (19). Conjugated $\left[{ }^{3} \mathrm{H}\right]$ bilirubin $(50$ $\mathrm{mCi} / \mathrm{mmol}$ ) was processed in an identical manner from bile collected after injection of a rat with $\alpha-\left[2,3-{ }^{3} \mathrm{H}\right]$ aminolevulinic acid. The conjugated material, consisting of a mixture of bilirubin monoglucuronide and bilirubin diglucuronide, was used to obtain preparations of these derivatives free from each other. The lyophilized mixture of conjugates in $2 \mathrm{ml}$ of $20 \mathrm{mM}$ phosphate-buffered saline at $\mathrm{pH} 5.8$ was extracted twice with $2 \mathrm{vol}$ of chloroform to remove traces of unconjugated bilirubin. The diglucuronide was prepared from the aqueous phase by chromatography on Sephadex G-25 $(2 \times 20 \mathrm{~cm})$ as described (19). The monoglucuronide was prepared by application of another portion of the extract to a column of Sephadex G-25 $(1.5 \times 25 \mathrm{~cm})$, washing with $100 \mathrm{ml}$ of $20 \mathrm{mM}$ phosphate-buffered saline at $\mathrm{pH} 7.0$, and eluting with $30 \mathrm{ml}$ of water. The eluate was lyophilized, dissolved in $1.5 \mathrm{ml}$ of $50 \%$ ( $\mathrm{vol} / \mathrm{vol}$ ) ethanol, and charged onto Sephadex LH-20 (1.5 × $25 \mathrm{~cm})$. As described (21), elution with $95 \%$ ethanol revealed two distinct pigment peaks; the initial limb of the second peak contained exclusively bilirubin monoglucuronide as demonstrated by ethyl anthranilate diazotization followed by thin-layer chromatography (22). The desired fractions were pooled and dried under reduced pressure at $4^{\circ} \mathrm{C}$.

Glutathione S-transferases A (12), AA (23), B (11), and C (11) were purified to homogeneity from livers of male SpragueDawley rats (Grand Island Biological Co., Grand Island, N. Y.). The human glutathione $S$-transferases were prepared from the liver of a normal white male who died after an automobile accident (15).

Radioactivity measurement. Radioactivity was quantitated with a liquid scintillation spectrometer (New England Nuclear, Boston, Mass., model 6847) after addition of up to $0.5 \mathrm{ml}$ of sample to $15 \mathrm{ml}$ of Aquasol (New England Nuclear) in a glass scintillation vial. Correction for quenching was made by addition of $20 \mu$ l of $\left[{ }^{3} \mathrm{H}\right]$ toluene $(4.4$ $\times 10^{4} \mathrm{dpm} / \mathrm{ml}$; New England Nuclear) as an internal standard to each sample. Counting efficiency was $45-50 \%$ for all samples.

Determination of the forms of hepatic bilirubin. Male Sprague-Dawley (Taconic Farms Inc., Germantown, N. Y.) or Wistar R (Universite Catholique de Louvain, Belgium) rats, 250-

1 Throughout this paper, "bilirubin" refers to the unconjugated pigment unless specified to the contrary.
$325 \mathrm{~g}$, maintained under light ether anesthesia, were used in all animal studies. $\left[{ }^{3} \mathrm{H}\right]$ Bilirubin $(4-5 \mu \mathrm{Ci})$ was dissolved in 100 $\mu l$ of $0.1 \mathrm{M} \mathrm{NaOH}$ and $1 \mathrm{ml}$ of rat plasma was added. A jugular catheter of polyethylene 10 tubing (Clay-Adams, Div. Becton, Dickinson \& Co., Parsippany, N. J.) was inserted and $0.8-1.0 \mathrm{ml}$ of the solution was injected. At timed intervals after injection, an abdominal incision was performed and the liver was quickly removed and placed in $20 \mathrm{mM}$ sodium phosphate at $\mathrm{pH} 7.4$ containing $0.25 \mathrm{M}$ sucrose at $4^{\circ} \mathrm{C}$. The liver was homogenized by hand with 20 strokes in a glass homogenizer cooled in ice. A small aliquot of the homogenate was removed for bilirubin fractionation and the remainder was centrifuged at $4^{\circ} \mathrm{C}$ and $2,000 \mathrm{~g}$ for $15 \mathrm{~min}$. The supernatant fluid was centrifuged at $4^{\circ} \mathrm{C}$ and $140,000 \mathrm{~g}$ for $70 \mathrm{~min}$, and the pellet was discarded.

The presence of conjugated bilirubin in homogenate and cytosol was demonstrated by diazotization of $0.5 \mathrm{ml}$ of each sample with $p$-iodoaniline $(24,25)$ and extraction of the azopigments in $0.4 \mathrm{ml}$ of $n$-butyl acetate. Standard preparations of unlabeled conjugated and unconjugated $p$-iodoaniline azopigments were obtained by diazotization of rat bile and of bilirubin, respectively. These nonradioactive azopigments were also extracted into $n$-butyl acetate; $30 \mu \mathrm{l}$ of each extract was added to $0.2 \mathrm{ml}$ of a $n$-butyl acetate extract from the radioactive samples being assayed. The resulting azopigment mixture was applied to a silica gel-G thinlayer chromatography plate $(250 \mu \mathrm{m}$; Analtech Inc., Newark, Del.) and developed for $40 \mathrm{~min}$ in chloroform-methanolwater (65:25:3) (25). Addition of the cold carrier pigments made possible visual identification of the bands corresponding to conjugated and unconjugated azopigments. These bands were scraped from the plate and placed directly into $15 \mathrm{ml}$ of Aquasol for measurement of radioactivity.

The proportion of conjugated to unconjugated bilirubin in whole homogenates and cytosols was determined separately by a modification of the Weber-Schalm partition (26), using $100 \mu$ l of sample. In the modified procedure, diazo reagent was omitted from the extraction mixture, and the volume of all other reagents was reduced in proportion to the sample size. Extraction mixtures (a $950-\mu$ l total volume) were shaken in glass-stoppered conical centrifuge tubes with a 2-ml capacity. After allowing the phases to separate, measured aliquots of the upper (polar) and lower (nonpolar) layers were aspirated and transferred to counting vials with finetipped micropipettes, with care taken not to include any of the interface in the aspirated sample. The amount of radioactivity partitioning into each layer was determined by correcting the volume of the aliquot removed to the experimentally predetermined volume of the appropriate layer. Application of the Weber-Schalm partition to homogenate and cytosol preparations often resulted in a coagulum of precipitated protein at the interface. To insure that appreciable quantities of radiobilirubin were not trapped in this interface, the recovery of label in the upper and lower layers was compared with the radioactivity in an equivalent volume of sample which was counted directly in Aquasol.

The following additional control studies were performed to assess performance of the modified Weber-Schalm partition. (a) Either $\left[{ }^{3} \mathrm{H}\right]$ bilirubin or conjugated $\left[{ }^{3} \mathrm{H}\right]$ bilirubin, respectively, was added in vitro to liver homogenates from two untreated Sprague-Dawley rats. These homogenates were used for the preparation of cytosol, as described above, and aliquots of both homogenate and cytosol were subjected to the modified Weber-Schalm partition in a manner similar to the experimental samples. (b) Validity of the partition system for endogenously administered bilirubin was examined by studying partition of radioactivity in homogenates and cytosols from the liver of a jaundiced Gunn 
rat injected $24 \mathrm{~h}$ previously with $6 \mu \mathrm{Ci}\left[{ }^{3} \mathrm{H}\right.$ ]bilirubin, and from seven Sprague-Dawley rats injected $4 \mathrm{~min}$ previously with $1.5 \mu \mathrm{Ci}$ conjugated [ ${ }^{3} \mathrm{H}$ ]bilirubin. (c) Partitioning of $\left[{ }^{3} \mathrm{H}\right]$ bilirubin monoglucuronide was assessed with pigment preparations which were partially purified from SpragueDawley rat bile by albumin-agarose affinity chromatography (19). By differential elution (19), a series of seven conjugated bilirubin samples containing $74-83 \%$ bilirubin monoglucuronide and a second series of nine samples containing only 15-23\% monoglucuronide were obtained. Each lyophilized sample was dissolved in saline, and subjected to the micro-modification of the Weber-Schalm system as described above. $(d)$ Finally, the possibility that some radioactive unconjugated bilirubin could be carried into the polar layer of the solvent partition system by complexing with bilirubin diglucuronide was assessed in studies in which an equimolar quantity of unlabeled bilirubin diglucuronide (in the form of Wistar $R$ rat bile) was added to samples of hepatic homogenate and hepatic cytosol of a jaundiced Gunn rat previously injected in vivo with $\left[{ }^{3} \mathrm{H}\right]$ bilirubin. $\left[{ }^{3} \mathrm{H}\right]$ Bilirubin and conjugated $\left[{ }^{3} \mathrm{H}\right]$ bilirubin content in all $100-\mu l$ aliquots which were partitioned was $20-100$ pmol.

Appearance of conjugated bilirubin in bile. In each of three Sprague-Dawley rats maintained under light ether anesthesia, a polyethylene 10 catheter was inserted into the jugular vein. A second polyethylene 10 catheter was placed in the common bile duct just proximal to the duodenum and advanced into the hilum. $\left[{ }^{3} \mathrm{H}\right]$ Bilirubin $(4-5 \mu \mathrm{Ci})$ was injected intravenously and all bile was collected into preweighed glass scintillation vials. For the first $20 \mathrm{~min}$, vials were changed at 2-min intervals, and capped tightly. Between 20 and 35 min, bile was allowed to flow freely into a plastic tuberculin syringe; the total volume was noted and an aliquot was placed into a tared vial. Subsequently, bile was collected at 15 -min intervals, and the study was terminated at $90 \mathrm{~min}$. The weight of bile collected at each interval was determined after weighing the capped vials. The specific gravity of bile was obtained by weighing a known aliquot collected between 20 and $35 \mathrm{~min}$; this value was assumed to remain constant over the course of the experiment. Bile volume (bile weight divided by its specific gravity) was determined for each sample and bile flow (milliters per minute) was derived. The volume of bile contained within the dead space of the catheter was calculated from the internal diameter $(0.011$ inch) and its length. The time necessary to fill the dead space with bile represents the time lag for bile to reach the collecting vial after appearance at the hilum. Because flow was found to be constant, this time period remained constant throughout each study and was subtracted in subsequent data analysis. After weighing each bile sample, $15 \mathrm{ml}$ of Aquasol was added and radioactivity was measured.

In two additional rats, bile was collected in 2-min aliquots for $20 \mathrm{~min}$ after injection of $5 \mu \mathrm{Ci}\left[{ }^{3} \mathrm{H}\right]$ bilirubin. Each aliquot was diluted in saline to a final bilirubin concentration of $2-5 \mathrm{mg} / 100 \mathrm{ml}$ and diazotized with $p$-iodoaniline. After addition of cold carrier to facilitate identification of the azo bands, the azopigments were separated by thin-layer chromatography as described above. The radioactivity detected in conjugated and unconjugated azopigments was determined, and the proportion of the injected $\left[{ }^{3} \mathrm{H}\right]$ bilirubin excreted as monoglucuronide was calculated for each 2-min time period. Quantities of bilirubin in each 2-min sample did not permit determination of absolute amounts of mono- and diglucuronide present.

Affinity of glutathione S-transferases for bilirubin and its glucuronides. Binding affinities were evaluated by measuring the decrease in the intrinsic fluorescence of each glutathione $S$-transferase upon the addition of ligand. Such changes in fluorescence as appear with these enzymes (16) are due to an increase in the polarity of the environment of a protein tryptophan occasioned by the ligand (27). Either a Farrand Mark I spectrofluorimeter (Farrand Optical Co., Inc., Valhalla, N. Y.) with cuvettes containing a $100-\mu l$ total volume, or a Perkin-Elmer Fluorescence Spectrometer MPF-3 (Perkin-Elmer Corp., Mountain View, Calif.) $300-\mu$ l total volume, was used. The cuvettes contained $0.2-$ $1.2 \mu \mathrm{M}$ protein, $6 \%$ glycerol, $0.1 \mathrm{mM}$ glutathione, and $0.1 \mathrm{M}$ potassium phosphate at $\mathrm{pH}$ 7.5. Temperature was maintained at $25^{\circ} \mathrm{C}$. For the transferases, the change in fluorescence was measured at the $330-\mathrm{nm}$ maximum after excitation at $285 \mathrm{~nm}$. The absorbance of solutions of bilirubin and its glucuronides was sufficiently low that correction for inner filter effects (27) was not needed; correction was made for dilution and neither bilirubin nor its mono- and diglucuronides fluoresced at the relevant wavelengths. A plot of the reciprocal of the change in fluorescence against the reciprocal of the total ligand concentration (16) was evaluated by linear least squares regression. Dissociation constants were calculated as the negative reciprocal of the $x$-intercept.

Statistical analysis was performed using Student's $t$ test and linear least squares regression (28).

\section{RESULTS}

Weber-Schalm partition. When 50 samples of rat plasma containing either conjugated $\left[{ }^{3} \mathrm{H}\right]$ bilirubin or unconjugated $\left[{ }^{3} \mathrm{H}\right]$ bilirubin were extracted with the micro-modification of the Weber-Schalm partition system, $96.3 \pm 2.6 \%$ (SE) of the radioactivity present was recovered in the two layers of the solvent system. Application of the same system to 146 samples of hepatic homogenate or cytosol from these studies, containing either conjugated $\left[{ }^{3} \mathrm{H}\right]$ bilirubin or unconjugated $\left[{ }^{3} \mathrm{H}\right.$ ]bilirubin, led to recovery of $98.2 \pm 1.2 \%$ of the radioactivity present. Hence, the development of a coagulum of denatured proteins at the phase interface of this system, when it is applied to liver homogenates or cytosols, does not entrap significant amounts of either unconjugated or conjugated bilirubin.

When added to rat plasma, $91 \pm 1.1 \%$ of conjugated $\left[{ }^{3} \mathrm{H}\right]$ bilirubin $(n=11)$ and $91 \pm 1.3 \%$ of unconjugated $\left[{ }^{3} \mathrm{H}\right]$ bilirubin $(n=14)$ partitioned into the upper (polar) and lower (nonpolar) phases, respectively, of this system. When conjugated or unconjugated $\left[{ }^{3} \mathrm{H}\right]-$ bilirubin were added in vitro to rat liver homogenate, both Weber-Schalm partitioning data and determination of the relative proportion of unconjugated (azo A $)^{2}$ and conjugated (azo B) azopigments were identical to values obtained with the pigments before admixture with the homogenates (Table I). Similarly, after administration of conjugated $\left[{ }^{3} \mathrm{H}\right]$ bilirubin to SpragueDawley rats and unconjugated $\left[{ }^{3} \mathrm{H}\right]$ bilirubin to a Gunn rat in vivo, an average of $95 \%$ (Sprague-Dawley) and $94 \%$ (Gunn) of the radioactivity in corresponding

${ }^{2}$ Abbreviations used in this paper: azo A, unconjugated azopigments; azo B, conjugated azopigments. 
TABLE I

Recovery of Unconjugated $\left[{ }^{3} \mathrm{H}\right]$ Bilirubin and Conjugated $\left[{ }^{3} \mathrm{H}\right]$ Bilirubin upon Addition to Rat Liver Homogenate

\begin{tabular}{lccc}
\hline \multicolumn{1}{c}{ Preparation } & Recovery & $\begin{array}{c}\text { 'H in polar } \\
\text { phase }\end{array}$ & $\begin{array}{c}\text { Conjugated } \\
\text { azopigment }\end{array}$ \\
\hline & $\%$ & $\%$ & $\%$ \\
[ ${ }^{3} \mathrm{H}$ ]bilirubin added & - & 9 & $<1$ \\
Recovery in homogenate & 101 & 11 & $<1$ \\
Recovery in cytosol & 63 & 8 & $<1$ \\
$\begin{array}{l}\text { Conjugated [ }{ }^{3} \mathrm{H} \text { ]bilirubin } \\
\text { added }\end{array}$ & - & 93 & 74 \\
Recovery in homogenate & 100 & 91 & 74 \\
Recovery in cytosol & 55 & 94 & 75 \\
\hline
\end{tabular}

* All values are the average of two experiments.

hepatic homogenates partitioned into the upper and lower layers, respectively, of the partition system. In a separate experiment, equimolar quantities of bilirubin diglucuronide (in the form of Wistar $R$ rat bile) were added to the native unconjugated bilirubin in the hepatic homogenate from a Gunn rat which previously had been labeled in vivo with unconjugated ${ }^{3} \mathrm{H}$ bilirubin. There was no effect on the partitioning of label. In 10 replicate samples, $94 \pm 2.5 \%$ of the isotope partitioned into the lower layer before and $95 \pm 1.2 \%$ after addition of the conjugated pigment.

Additionally, studies of the partition of conjugated $\left[{ }^{3} \mathrm{H}\right]$ bilirubin samples containing either $74-83$ or $15-$ $23 \%$ bilirubin monoglucuronide indicated that an average of $\geq 91 \%$ of both preparations distributed into the polar layer. Nevertheless, the value for the seven samples containing predominantly monoglucuronide $(91 \pm 0.9 \%)$ was slightly but significantly less than the value obtained with nine samples which were principally diglucuronide $(94 \pm 0.2 \% ; P<0.01)$.

Hepatic bilirubin. Rapid uptake of radioactivity by liver ensued immediately after injection of SpragueDawley rats with $\left[{ }^{3} \mathrm{H}\right]$ bilirubin (Fig. 1). As early as $1.5 \mathrm{~min}$ after injection, $36 \%$ of the injected dose was

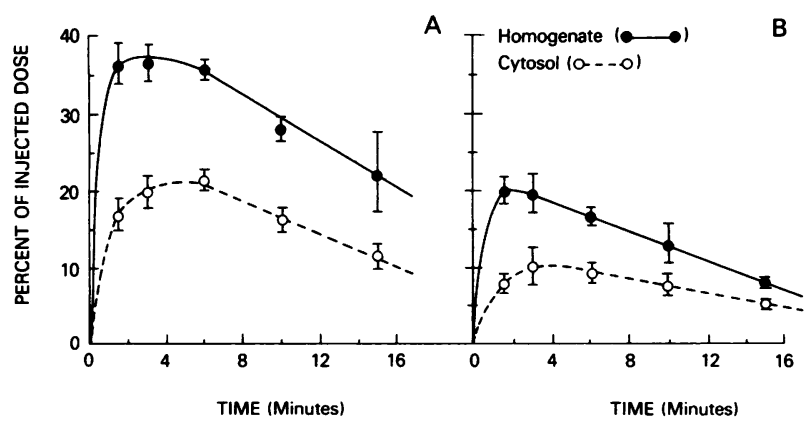

FIGURE 1 Recovery in rat liver homogenate (O) and cytosol (O) of ${ }^{3} \mathrm{H}(\mathrm{A})$ and of conjugated $\left[{ }^{3} \mathrm{H}\right]$ bilirubin (B) as a percentage of the injected dose of $\left[{ }^{3} \mathrm{H}\right]$ bilirubin. accounted for in liver homogenates and $20 \%$ was recovered in the cytosol. Between 3 and $15 \mathrm{~min}$, hepatic content of radioactive material declined from 37 to $23 \%$ of the injected dose and was similarly reflected in the cytosol component. Of significance is the finding that $37-64 \%$ of the radioactivity in the cytosol and 44$64 \%$ in the entire homogenate was present as conjugated bilirubin, i.e. as radioactivity partitioning into the polar phase by the method of Weber and Schalm (26).

That the radioactive material represented bilirubin or its conjugates, and not breakdown products, was verified when the $p$-iodoaniline diazo derivatives of each sample of liver were examined $(24,25)$. In the diazo reaction, the tetrapyrrole structure of bilirubin is cleaved into two dipyrrole molecules. $1 \mathrm{~mol}$ of bilirubin forms $2 \mathrm{~mol}$ of azo A; $1 \mathrm{~mol}$ of bilirubin diconjugate forms $2 \mathrm{~mol}$ of azo B; $1 \mathrm{~mol}$ of bilirubin monoconjugate forms $1 \mathrm{~mol}$ of azo $A$ and $1 \mathrm{~mol}$ of azo $B$ (29). Thin-layer chromatography of the azopigments generated from the liver samples demonstrated that over $90 \%$ of radioactivity applied to the plates was recovered as either azo A or azo B. Between 3 and 15 min after injection, the proportion of radioactivity distributing as azo B in both cytosol and homogenate was $\cong 50 \%$ of total conjugated bilirubin as determined by Weber-Schalm partition (Table II), thereby strongly suggesting that the predominant form of bilirubin present was the monoconjugated derivative. In view of the experimental liminations of this system, the presence of small quantities of bilirubin diglucuronide could not entirely be excluded.

Entirely similar experiments were performed with the Wistar R-strain rats in which a greater proportion of biliary bilirubin is excreted as the diglucuronide $(19,22)$. As in the case for Sprague-Dawley rats, rapid accumulation of radioactive material in liver was demonstrated with $>50 \%$ in conjugated form. A small excess of polar partitioning radioactivity was noted, which could not be accounted for by conjugated bilirubin as estimated by azopigment analysis. Nevertheless, these studies suggested that monoconjugates represented the bulk of the conjugated bilirubin present (Table II).

Rates of appearance of bilirubin in bile. Because of concern that the observed hepatic conjugated bilirubin was the result of contamination by intrahepatic bile, an attempt was made to assess the rate of appearance of radioactivity in bile itself. After injection of [ $\left.{ }^{3} \mathrm{H}\right]$ bilirubin, 3-4 min passed before radioactivity was found in bile, after correction for dead space (Fig. 2). The subsequent cumulative appearance of radioactivity could be well approximated for each of the three animals by a straight line for the period of 4-20 min after injection (Fig. 2). A least squares fit of the data obtained for each animal revealed a slope of $3.0 \pm 0.2 \%$ 
Table II

Comparison of Conjugated Bilirubin with its Derived Conjugated Azopigment from Rat Liver*

\begin{tabular}{|c|c|c|c|c|c|c|}
\hline \multirow[b]{2}{*}{ Strain } & \multirow{2}{*}{$\begin{array}{c}\text { Time } \\
\text { after } \\
\text { injection }\end{array}$} & \multirow[b]{2}{*}{$\begin{array}{l}\text { No. of } \\
\text { rats }\end{array}$} & \multicolumn{2}{|c|}{ Homogenate } & \multicolumn{2}{|c|}{ Cytosol } \\
\hline & & & $\begin{array}{c}\text { Conjugated } \\
\text { bilirubin }\end{array}$ & Azo B & $\begin{array}{c}\text { Conjugated } \\
\text { bilirubin } \$\end{array}$ & Azo B $\$$ \\
\hline & $\min$ & & $\%$ of total & \% Azopigment & $\%$ of total & $\%$ Azopigment \\
\hline Sprague- & 1.5 & 3 & $44 \pm 0.3$ & $15 \pm 0.9$ & $37 \pm 1.5$ & $14 \pm 0.3$ \\
\hline \multirow[t]{4}{*}{ Dawley } & 3 & 2 & $55 \pm 0.5$ & $27 \pm 3.5$ & $52 \pm 5.5$ & $26 \pm 2.5$ \\
\hline & 6 & 4 & $64 \pm 1.2$ & $28 \pm 1.2$ & $56 \pm 4.4$ & $26 \pm 3.3$ \\
\hline & 10 & 3 & $57 \pm 5.0$ & $27 \pm 4.1$ & $61 \pm 1.5$ & $32 \pm 0.9$ \\
\hline & 15 & 3 & $54 \pm 6.6$ & $27 \pm 6.0$ & $64 \pm 2.5$ & $34 \pm 1.7$ \\
\hline \multirow[t]{2}{*}{ Wistar R } & 1.5 & 2 & $50 \pm 9.0$ & $21 \pm 4.5$ & $45 \pm 9.0$ & $16 \pm 2.5$ \\
\hline & 3 & 2 & $56 \pm 0$ & $22 \pm 0$ & $51 \pm 1.5$ & $17 \pm 1.0$ \\
\hline
\end{tabular}

* Results expressed as mean $\pm \mathrm{SEM}$.

† Conjugated bilirubin is presented in terms of the percent of the total amount of bilirubin and its derivatives; this value was obtained from the polar phase of a Weber-Schalm partition.

$\$$ Radioactivity in the azo B area of chromatograms as a percentage of the sum of radioactivity in azo $A$ and azo $B$.

of the injected dose excreted per minute. It will be obvious that such a curve-fitting procedure does not imply that bile excretion is zero order; rather, the apparent linearity represents a linear approximation over the initial short period.

From these data, limits can be calculated for the possibility of contamination in liver homogenates by intrahepatic bile. The animals used had livers weighing $10-14 \mathrm{~g}$ and a bile flow of $0.02 \mathrm{ml} / \mathrm{min}$. Because the dead space volume of the rat intrahepatic biliary tree is $5 \mu \mathrm{l} / \mathrm{g}$ of liver (30), the total intrahepatic bile would be that volume of bile that appears at the

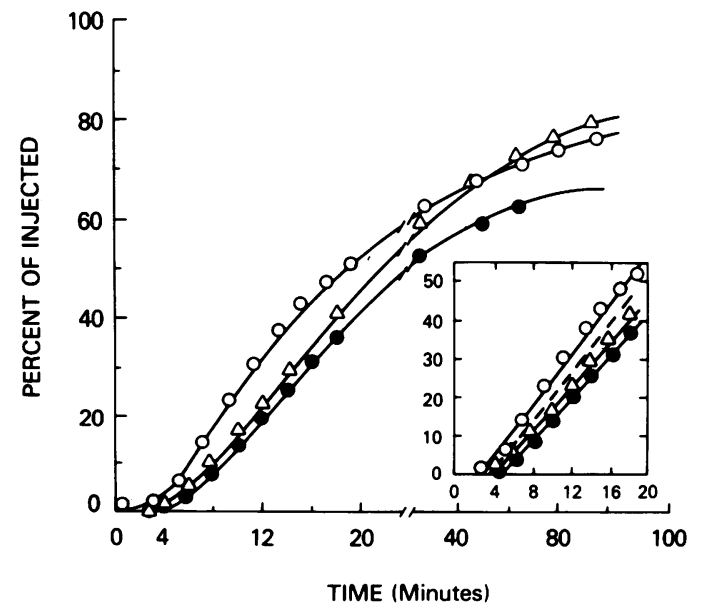

FIgURE 2 Cumulative appearance of ${ }^{3} \mathrm{H}$ in bile after injection of rats with $\left[{ }^{3} \mathrm{H}\right]$ bilirubin. The insert illustrates the linear least squares fit to the initial $20 \mathrm{~min}$ of each study; the broken line illustrates the linear least squares fit to all the data combined and has a slope of $3 \%$ of the injected dose per minute. hilum and is collected during a 3- to 4-min period. It may be calculated from Fig. 2 that, at 1.5 min, retained intrahepatic bile contains substantially $<5 \%$ of the injected dose of $\left[{ }^{3} \mathrm{H}\right]$ bilirubin. Liver homogenates were found to contain $36 \%$ of the injected dose at $1.5 \mathrm{~min}$, including $17 \%$ as conjugated bilirubin, an amount far exceeding possible contamination by intrahepatic bile. As demonstrated in Fig. 1, between 3 and $15 \mathrm{~min}$ after injection there is a significant decline in hepatic content of conjugated $\left[{ }^{3} \mathrm{H}\right]$ bilirubin. However, the relatively small contribution due to retained intrahepatic bile is constant over this time period (Fig. 2). The data, therefore, point to a pool of $\left[{ }^{3} \mathrm{H}\right]$ bilirubin conjugates retained in the liver, a pool that is released into bile at an approximately constant rate (Fig. 2).

The nature of the ${ }^{3} \mathrm{H}$-conjugates appearing in bile after injection of $\left[{ }^{3} \mathrm{H}\right]$ bilirubin is illustrated in Table III. In both animals, there was a tendency for a more rapid initial excretion of $\left[{ }^{3} \mathrm{H}\right]$ bilirubin monoglucuronide, after which the proportion of radiolabeled monoconjugate gradually declined toward a constant level. Base-line excretion was found experimentally to be $75 \%$ monoconjugate in rat $\mathrm{A}$. This variable was not determined in rat $\mathrm{B}$, but presumably approximated the $75-80 \%$ value found in similar Sprague-Dawley animals.

Binding proteins. The accumulation of both bilirubin and its conjugates in liver raises the question of the manner in which they are stored. Arias and his colleagues have demonstrated the presence of a protein, ligandin, with a high affinity for the otherwise insoluble bilirubin $(4,7,8)$. After the identification of ligandin as glutathione $S$-transferase B (9), it was found that all of the glutathione transferases were relatively avid binding proteins for bilirubin 
TABLE III

Excretion of Conjugated $\left[{ }^{3} \mathrm{H}\right]$ Bilirubin in Bile after Intravenous Administration of $\left[{ }^{3} \mathrm{H}\right]$ Bilirubin

\begin{tabular}{|c|c|c|}
\hline \multirow[b]{2}{*}{ Time } & \multicolumn{2}{|c|}{$\begin{array}{c}\text { Percent of labeled } \\
\text { conjugates excreted as } \\
\text { bilirubin monoglucuronide* }\end{array}$} \\
\hline & Rat A & Rat B \\
\hline \multicolumn{3}{|l|}{$\min$} \\
\hline $0-2$ & NC & NC \\
\hline $2-4$ & 100 & 100 \\
\hline $4-6$ & 100 & 100 \\
\hline $6-8$ & 90 & 88 \\
\hline $8-10$ & 91 & 92 \\
\hline $10-12$ & 81 & 89 \\
\hline $12-14$ & 82 & 89 \\
\hline $14-16$ & 72 & 88 \\
\hline $16-18$ & 79 & 85 \\
\hline $18-20$ & 75 & 83 \\
\hline $20-22$ & 74 & - \\
\hline
\end{tabular}

* Proportion of monoglucuronide was determined from thinlayer chromatographic analysis of $\boldsymbol{p}$-iodoaniline azopigments. \$ No counts detected.

$(15,16)$. A plot of the data for glutathione $S$-transferase B (ligandin) with each of the tested ligands is presented in Fig. 3. The dissociation constants of each of the homogenous transferases for bilirubin and its glucuronides are presented in Table IV. It will be

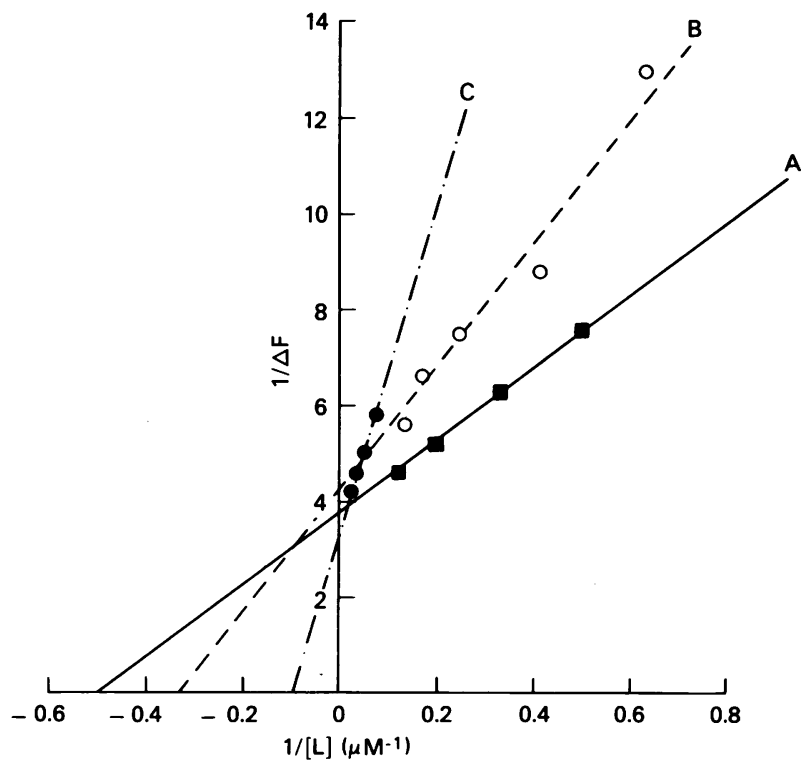

Figure 3 Double reciprocal plot of the decrement in fluorescence of rat glutathione $S$-transferase $B(\Delta F)$ as a function of added ligand concentration $(\mathrm{L})$. The ligands are unconjugated bilirubin (A), bilirubin monoglucuronide (B), and bilirubin diglucuronide $(C)$. Dissociation constants are calculated as the negative reciprocals of the $\mathrm{x}$-intercepts.
TABLE IV

Binding of Bilirubin and its Glucuronides with the Glutathione S-Transferases from Rat and Human Liver

\begin{tabular}{|c|c|c|c|}
\hline \multirow[b]{2}{*}{ Transferase } & \multirow[b]{2}{*}{ Bilirubin } & \multicolumn{2}{|c|}{ Dissociation constant $\left(K_{d}\right)$} \\
\hline & & Monoglucuronide & Diglucuronide \\
\hline & & $K_{d} \times 10^{-6}$ & \\
\hline Rat A & 15 & 2 & 23 \\
\hline $\mathbf{A A}$ & 100 & 4 & 40 \\
\hline B & 2 & 3 & 10 \\
\hline C & 2 & 6 & 20 \\
\hline Human $\delta$ & 18 & 5 & 33 \\
\hline$\epsilon$ & 33 & 5 & 121 \\
\hline
\end{tabular}

Data were obtained by following the decrease in intrinsic fluorescence of the protein by the method described for the binding of bilirubin (16).

evident that the transferases from both rat and human liver have low dissociation constants for bilirubin as well as for both glucuronide conjugates. Thus, each of the transferases is capable of tightly binding bilirubin conjugates.

\section{DISCUSSION}

An obligatory step in the normal pattern of excretion of bilirubin is the formation of more polar conjugates $(6,31)$. The nature of the conjugates and their proportion varies with the species $(32,33)$. Indeed, differences were noted between the two strains of rats used here: bile from Sprague-Dawley rats contains primarily bilirubin monoglucuronide with only $10-20 \%$ as the diconjugate (10); bile from the Wistar R-strain contains $50-70 \%$ diconjugated bilirubin $(19,32)$.

The accumulation or "storage" of bilirubin in liver has been described $(2,34,35)$ and is supported by the present data. The low water solubility of bilirubin argues against its existence in a free state (36), but the discovery of ligandin and the subsequent recognition that the other glutathione $S$-transferases serve as organic anion-binding proteins $(4,9,16)$ provides an explanation for the intracellular accumulation of free bilirubin in concentrations that would otherwise lead to its precipitation. It has been postulated that conjugation of cholephilic anions such as bilirubin would result in compounds with reduced affinity for the binding proteins, enabling the conjugates to be readily excreted (17). A previous study has suggested that conjugated bilirubin does not accumulate in liver and that, once formed, immediately enters the bile (18). From data presented here, these conclusions must be modified. We have demonstrated significant quantities of monoconjugated bilirubin in liver and conclude that 
this represents intrahepatocellular accumulation, i.e., storage. The high affinity of the glutathione $S$-transferases for bilirubin and its glucuronides is presumably responsible for this phenomenon. The normally large amounts of these enzymes in liver, e.g. 3 and $10 \%$ of the total soluble protein of extracts from human (15) and rat (10) liver, respectively, are sufficient to account for the quantities of intrahepatic pigments observed.

Because the high affinities of the glutathione $S$-transferases for both bilirubin mono- and diglucuronides, it is surprising that the intrahepatic pool of conjugated bilirubin consists so predominantly of monoglucuronide. If both conjugates were formed by the microsomal enzyme, bilirubin UDPglucuronyltransferase, then these findings would imply a very rapid and highly preferential excretion of the diglucuronide by the canalicular transport system. The data in Table III are not consistent with this hypothesis.

An alternative explanation centers on the recent observations of Jansen et al. (37). They confirmed earlier data $(5,38)$ indicating that the monoglucuronide was the only bilirubin conjugate produced by the microsomal conjugating mechanism. In addition, they presented evidence that the conversion of bilirubin monoglucuronide to the diglucuronide occurs by a transesterification step not requiring UDPglucuronicacid as a cofactor, and catalyzed by an enzyme preparation localized to the liver cell plasma membrane, and present in highest concentration in the canalicular-enriched membrane fractions. Hence, one may speculate that the formation of bilirubin diglucuronide occurs at the canalicular plasma membrane, in a site or configuration which facilitates its immediate biliary excretion, without intracellular binding or accumulation. Such a hypothesis would explain our failure to demonstrate significant quantities of bilirubin diglucuronide even in the livers of Wistar $R$ rats, in which it is the predominant biliary bile pigment.

The results of the current investigation require a revision of the previously held beliefs that conjugated bilirubin does not bind tightly to the intrahepatocytic organic anion-binding proteins (17), and that, perhaps in consequence, it does not accumulate in normal liver (18). Our data demonstrate retention of conjugated bilirubin within the liver, and tight binding of bilirubin conjugates to the glutathione $S$-transferases. A satisfactory explanation for the observation that the intrahepatic pool of conjugated bilirubin consists predominantly of monoglucuronide clearly awaits further investigation.

\section{REFERENCES}

1. Berk, P. D., N. I. Berlin, and R. B. Howe. 1974. Disorders of bilirubin metabolism. In Duncan's Diseases of
Metabolism. P. K. Bondy and L. Rosenberg, editors. W. B. Saunders, Philadelphia. 7th edition. 825-880.

2. Goresky, C. A. 1965. The hepatic uptake and excretion of sulfobromophthalein and bilirubin. Can. Med. Assoc. J. 92: 851-857.

3. Scharschmidt, B. F., J. G. Waggoner, and P. D. Berk. 1975. Hepatic organic anion uptake in the rat. J. Clin. Invest. 56: $1280-1292$.

4. Levi, A. J., Z. Gatmaitan, and I. M. Arias. 1969. Two hepatic cytoplasmic fractions, $\mathrm{Y}$ and $\mathrm{Z}$, and their possible role in the hepatic uptake of bilirubin, sulfobromophthalein, and other anions. J. Clin. Invest. 48: 21562167.

5. Heirwegh, K. P. M., J. A. T. P. Meuwissen, and J. Fevery. 1973. Critique of the assay and significance of bilirubin conjugation. Adv. Clin. Chem. 16: 239-288.

6. Arias, I. M., L. Johnson, and S. Wolfson. 1961. Biliary excretion of injected conjugated and unconjugated bilirubin by normal and Gunn rats. Am. J. Physiol. 200: 1091-1094.

7. Reyes, H., A. J. Levi, Z. Gatmaitan, and I. M. Arias. 1971. Studies of $\mathrm{Y}$ and $\mathrm{Z}$, two hepatic cytoplasmic organic anion-binding proteins: effects of drugs, chemicals, hormones, and cholestasis. J. Clin. Invest. 50: 2242-2252.

8. Fleischner, G., J. Robbins, and I. M. Arias. 1972. Immunologic studies of Y-protein. A major cytoplasmic organic anion-binding protein in rat liver. J. Clin. Invest. 51: $677-684$.

9. Habig, W. H., M. J. Pabst, G. Fleischner, Z. Gatmaitan, I. M. Arias, and W. B. Jakoby. 1974. The identity of glutathione S-transferase B with ligandin, a major binding protein of liver. Proc. Natl. Acad. Sci. U.S.A. 71: 38793882.

10. Jakoby, W. B., W. H. Habig, J. H. Keen, J. N. Ketley, and M. J. Pabst. 1976. Glutathione S-transferases: Catalytic aspects. In Glutathione: Metabolism and Function. I. M. Arias and W. B. Jakoby, editors. Raven Press, New York. 189-211.

11. Habig, W. H., M. J. Pabst, and W. B. Jakoby. 1974. Glutathione S-transferases. The first enzymatic step in mercapturic acid formation. J. Biol. Chem. 249: 71307139.

12. Pabst, M. J., W. H. Habig, and W. B. Jakoby. 1974. Glutathione S-transferase A. J. Biol. Chem. 249: 71407150 .

13. Habig, W. H., J. H. Keen, and W. B. Jakoby. 1975. Glutathione S-transferase in the formation of cyanide from organic thiocyanates and as an organic nitrate reductase. Biochem. Biophys. Res. Commun. 64: 501-506.

14. Keen, J. H., W. H. Habig, and W. B. Jakoby. 1976. A mechanism for the several activities of the glutathione S-transferases. J. Biol. Chem. 251: 6183-6188.

15. Kamisaka, K., W. H. Habig, J. N. Ketley, I. M. Arias, and W. B. Jakoby. 1975. Multiple forms of human glutathione S-transferase and their affinity for bilirubin. Eur. J. Biochem. 60: 153-161.

16. Ketley, J. N., W. H. Habig, and W. B. Jakoby. 1975. Binding of non-substrate ligands to the glutathione transferases. J. Biol. Chem. 250: 8670-8673.

17. Erlinger, S., D. Dhumeaux, J. F. Desjeux, and J. P. Benhamou. 1973. Hepatic handling of unconjugated dyes in the Dubin-Johnson syndrome. Gastroenterology. 64: 106-110.

18. Bernstein, L. H., J. Ben Ezzer, L. Gartner, and I. M. Arias. 1966. Hepatic intracellular distribution of tritiumlabeled unconjugated and conjugated bilirubin in normal and Gunn rats. J. Clin. Invest. 45: 1194-1201.

19. Wolkoff, A. W., B. F. Scharschmidt, P. H. Plotz, and 
P. D. Berk. 1976. Purification of conjugated bilirubin: a new approach utilizing albumin-agarose gel affinity chromatography. Proc. Soc. Exp. Biol. Med. 152: 20-23.

20. Howe, R. B., P. D. Berk, J. R. Bloomer, and N. I. Berlin. 1970. Preparation and properties of specifically labeled radiochemically stable ${ }^{3} \mathrm{H}$-bilirubin.J. Lab. Clin. Med. 75: 499-502.

21. Ostrow, J. D., and N. H. Murphy. 1970. Isolation and properties of conjugated bilirubin from bile. Biochem. J. 120: $311-327$.

22. Heirwegh, K. P. M., G. P. Van Hees, P. Leroy, F. P. Van Roy, and F. H. Jansen. 1970. Heterogeneity of bile pigment conjugates as revealed by chromatography of their ethyl anthranilate azopigments. Biochem. J. 120: 877890.

23. Habig, W. H., M. J. Pabst, and W. B. Jakoby. 1976. Glutathione S-transferase AA from rat liver. Arch. Biochem. Biophys. 175: 710-716.

24. Van Roy, F. P., J. A. T. P. Meuwissen, F. de Meuter, and K. P. M. Heirwegh. 1971. Determination of bilirubin in liver homogenates and serum with diazotized p-iodoaniline. Clin. Chim. Acta. 31: 109-118.

25. Mertens, B. B. E., M. Van de Vijver, and K. P. M. Heirwegh. 1972. Determination of bilirubin in liver homogenate with diazotized p-iodoaniline. Improvement of color recovery by incorporation of antioxidant (2,6-ditert-butyl-p-cresol) in the reaction system. Anal. Biochem. 50: 652-655.

26. Weber, A. P. H., and L. Schalm. 1962. Quantitative separation and determination of bilirubin and conjugated bilirubin in human serum. Clin. Chim. Acta. 7: 805-810.

27. Brand, L., and A. Witholt. 1967. Fluorescence measurements. Methods Enzymol. 11: 776-856.

28. Snedecor, G. W., and W. G. Cochran. 1967. Statistical
Methods. The Iowa State University Press. Ames, Iowa. 6 th edition. $593 \mathrm{pp}$.

29. Heirwegh, K. P. M., J. Fevery, J. A. T. P. Meuwissen, J. de Groote, F. Compernolle, V. Desmet, and F. P. Van Roy. 1974. Recent advances in the separation and analysis of diazo-positive bile pigments. Methods Biochem. Anal. 22: 205-250.

30. G. Barber-Riley. 1963. Measurement of capacity of biliary tree in rats. Am. J. Physiol. 205: 1122-1126.

31. Schmid, R., J. Axelrod, L. Hammaker, and R. L. Swarm. 1958. Congenital jaundice in rats due to a defect in glucuronide formation. J. Clin. Invest. 37: 1123-1130.

32. Fevery, J., B. Van Damme, R. Michiels, J. de Groote, and K. P. M. Heirwegh. 1972. Bilirubin conjugates in bile of man and rat in the normal state and in liver disease. J. Clin. Invest. 51: 2482-2492.

33. Cornelius, C. E., K. C. Kelley, and J. A. Himes. 1975. Heterogeneity of bilirubin conjugates in several animal species. Cornell Vet. 65: 90-99.

34. Raymond, G. D., and J. T. Galambos. 1971. Hepatic storage and excretion of bilirubin in the dog. Am. J. Gastroenterol. 55: 119-134.

35. Raymond, G. D., and J. T. Galambos. 1971. Hepatic storage and excretion of bilirubin in man. Am. J. Gastroenterol. 55: 135-144.

36. Burnstine, R. C., and R. Schmid. 1962. Solubility of bilirubin in aqueous solutions. Proc. Soc. Exp. Biol. Med. 109: 356-358.

37. Jansen, P. L. M., J. R. Chowdhury, E. Fischberg, and I. M. Arias. 1977. An enzyme of liver plasma membrane which converts bilirubin monoglucuronide to bilirubin diglucuronide. J. Biol. Chem. 252: 2710-2716.

38. Jansen, P. L. M. 1974. The enzyme-catalyzed formation of bilirubin diglucuronide by a solubilized preparation from cat liver microsomes. Biochem. Biophys. Acta. 338: 170-182. 